\title{
Construction of intensity-duration-frequency (IDF) curves for precipitation with annual maxima data in Rwanda, Central Africa
}

\author{
G. R. Demarée and H. Van de Vyver \\ Royal Meteorological Institute of Belgium, Ringlaan 3, 1180 Brussels, Belgium
}

Correspondence to: G. R. Demarée (gaston.demaree@ meteo.be)

Received: 8 February 2013 - Revised: 8 May 2013 - Accepted: 14 May 2013 - Published: 25 June 2013

\begin{abstract}
Detailed probabilistic information on the intensity of precipitation in Central Africa is highly needed in order to cope with the risk analysis of natural hazards. In the mountainous areas of Rwanda land slides frequently occur and might cause a heavy toll in human lives. The establishment of Intensity-Duration-Frequency curves for precipitation in Central Africa remains a difficult task as adequate long-term data sets for short aggregation times are usually not available.

In 1962 recording raingauges were installed at several stations in Rwanda. According to the climatological procedures in use at that time in Congo, Rwanda and Burundi, maximum monthly and annual precipitation depths for fixed-time durations of 15, 30, 45, 60 and 120 min were determined from the rainfall charts. The data set is completed by the monthly and annual daily precipitation extremes from the non-recording raingauge at the stations.

The authors used the dataset to establish the IDF-curves for precipitation at 3 stations in Rwanda having more than $20 \mathrm{yr}$ of operation. The fixed-hour intervals of multiple $15 \mathrm{~min}$ require the use of a technique converting data from fixed-time intervals into data of arbitrary starting intervals. Therefore, the van Montfort technique was used.
\end{abstract}

\section{Introduction}

The purpose of this study is to establish Intensity-DurationFrequency (IDF) curves for precipitation at 3 climatological stations in Rwanda. These stations are located in zones with a different rainfall regime. The IDF-curves for precipitation provide a mathematical expression linking the intensity, the duration or, better said, the aggregation time of the rainfall and the frequency of a rainfall event (Stedinger et al., 1993). The establishment of IDF-curves for precipitation is a fre- quently used tool in water resources projects and management, sewer design in urban areas and geomorphologic research. In this case, a Montana-like formula is used as mathematical expression of the IDF-curves relationship. This formula has proven its adaptability to express IDF-curves for precipitation under different rainfall regimes.

Only short-time Annual Maxima (AM) information was available for the sub-daily durations. In Sect. 2 , the climate of Rwanda is briefly described and, in particular, the climatological aspects of the 3 stations are given. In Sect. 3, a Gumbel probability distribution is fitted to the AM data. Furthermore, the van Montfort technique is used to assess directly the parameters $\mu_{\mathrm{A}}$ and $\sigma_{\mathrm{A}}$ of the Gumbel probability distributions for A-maxima of 15, 30, 60 min and 1-day.

\section{Data and climate}

The Republic of Rwanda, known as the Land of a Thousand Hills, is a landlocked country located in the Great Lakes region of eastern-central Africa, bordered by Uganda, Burundi, the Democratic Republic of the Congo and Tanzania (Fig. 1). It covers an area of $26338 \mathrm{~km}^{2}$. The country is bounded in the west by a mountain zone running south-north with an altitude of between 2000 and $2500 \mathrm{~m}$. To the east of this range, the plateaus are at an altitude of approximately 1500 and $2000 \mathrm{~m}$. To the west of this range is situated Lake Kivu at $1460 \mathrm{~m}$ elevation. On the plateau the mean annual rainfall varies between 900 and $1200 \mathrm{~mm}$ while in the mountains it varies between 1200 and $1500 \mathrm{~mm}$. In the Kagera plains in the east part of Rwanda, rainfall amounts less $900 \mathrm{~mm}$ showing a tendency to aridity (Bultot and Griffiths, 1971).

In 1962 recording raingauges were installed at a number of stations at the Rwanda Agricultural Research Institute/Institut des Sciences Agronomiques du Rwanda (ISAR). 
Table 1. Name, geographical co-ordinates, altitude and operating service of the stations Karama-Plateau, Rubona and Rwerere-Colline in Rwanda.

\begin{tabular}{lcccc}
\hline Name & Longitude East & Latitude South & Altitude(m) & Service \\
\hline Karama-Plateau & $30^{\circ} 16^{\prime}$ & $02^{\circ} 17^{\prime}$ & 1403 & ISAR \\
Rubona & $29^{\circ} 46^{\prime}$ & $02^{\circ} 29^{\prime}$ & 1706 & ISAR \\
Rwerere-Colline & $29^{\circ} 53^{\prime}$ & $01^{\circ} 32^{\prime}$ & 2312 & ISAR \\
\hline
\end{tabular}

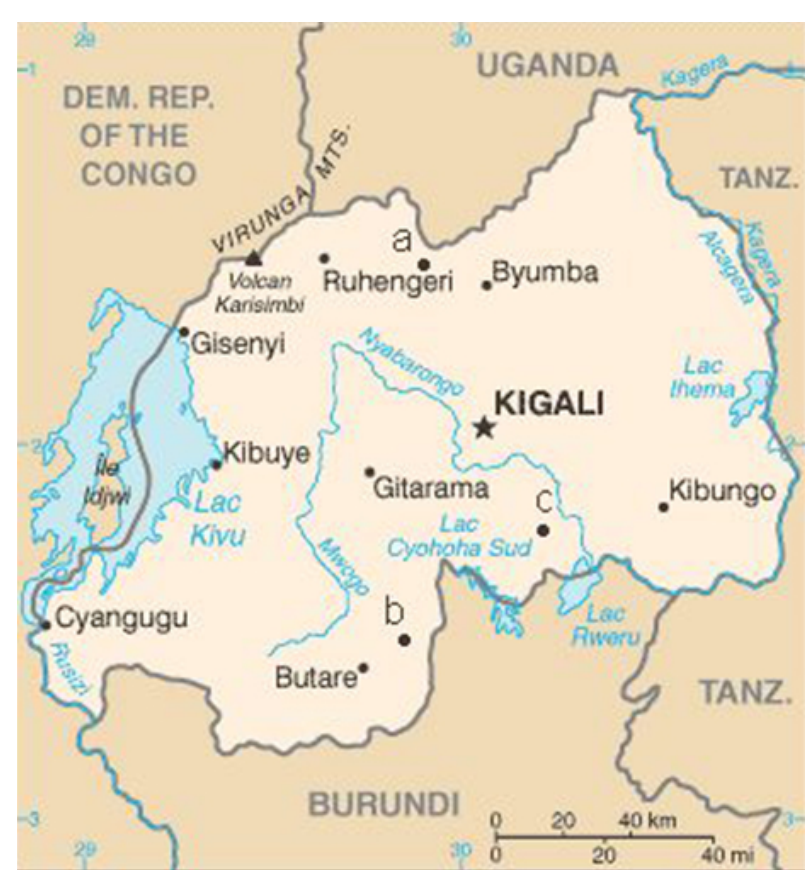

Fig. 1. Map of the Republic of Rwanda with the location of the stations, Rwerere-Colline (a), Rubona (b) and Karama-Plateau (c).

Monthly and annual precipitation depths, expressed in $0.1 \mathrm{~mm}$, for fixed-time durations of $15,30,45,60$ and 120 min were manually determined from the rainfall charts (Crabbé, 1971). The rainfall charts are read in fixed-time calendar $15 \mathrm{~min}$ interval. The data set is completed by the monthly and annual daily precipitation extremes from the non-recording raingauge. The sub-daily maxima data from the recording raingauge showed excellent agreement with the daily maxima data from the non-recording raingauge at the same station. The recording raingauge network continued its operation till, more or less, the mid-eighties. Data used in the present research were extracted from the annual publications Bulletin Climatologique Annuel mainly edited by ISAR. The AM extremes data set for the 3 stations abovementioned were available to the authors for the years 1962 till 1985. The 3 stations selected on the basis of the length of their record are respectively: Karama-Plateau, Rubona and Rwerere-Colline (Fig. 1). Table 1 represents their geographical characteristics. The length of the AM series is $20 \mathrm{yr}$ for the stations Karama-Plateau and Rwerere-Colline and $23 \mathrm{yr}$ for the station of Rubona. These data are the core rainfall intensity data of the present study. Daily data are available for slightly longer to longer reference periods and therefore AM data for the daily maxima are included in the approach.

The station Karama-Plateau belongs to the Semi Arid Research Centre (SARC) of the Rwanda Agricultural Research Institute (ISAR) and is situated in the Eastern Province, district of Bugesera, at an altitude of $1403 \mathrm{~m}$. The average annual precipitation is approximately $850 \mathrm{~mm}$. The station Rubona-Colline is at an altitude of $1706 \mathrm{~m}$. It received an average annual precipitation of $1240 \mathrm{~mm}$ over the reference period 1955-1990. The station Rwerere-Colline is part of the High Altitude Research Center (HARC) of ISAR. The station is located in the Northern Province, Rwerere sector, Burera district, at an altitude of $2312 \mathrm{~m}$ with an average annual rainfall of $1200 \mathrm{~mm}$.

\section{Methodology}

The Montana-type IDF-curve for precipitation was selected for the 3 stations:

$i_{T, d}=\frac{a(T)}{(d+\theta)^{\eta}}$

where $d$ is the length of the precipitation and $T$ is the return period of the event. The nominator $a(T)$ is independent of the aggregation time so that the family of curves in $T$ are parallel. The expression in the nominator is determined by the inverse function of $a(T)$ (Koutsoyiannis et al., 1998).

The denominator $(d+\theta)^{\eta}$ of the Montana-type of IDFcurve provides the shape of the IDF-curves; the dynamical parameters $\theta$ and $\eta$ describe the dynamics of the extreme rainfall process in function of the duration $d$ and are climaterelated.

As only annual maxima are available, the adequate probability distribution functions are the 2-parameter Gumbel distribution $G$ and the 3-parameter General Extreme Value (GEV) distribution. The cumulative distribution function of $G$ is given by:

$G(x ; \mu, \sigma)=\exp \left(-\exp \left(-\frac{x-\mu}{\sigma}\right)\right)$

where $x$ is the function variable, $\mu$ and $\sigma$ are the parameters of the Gumbel distribution function. They are called the 

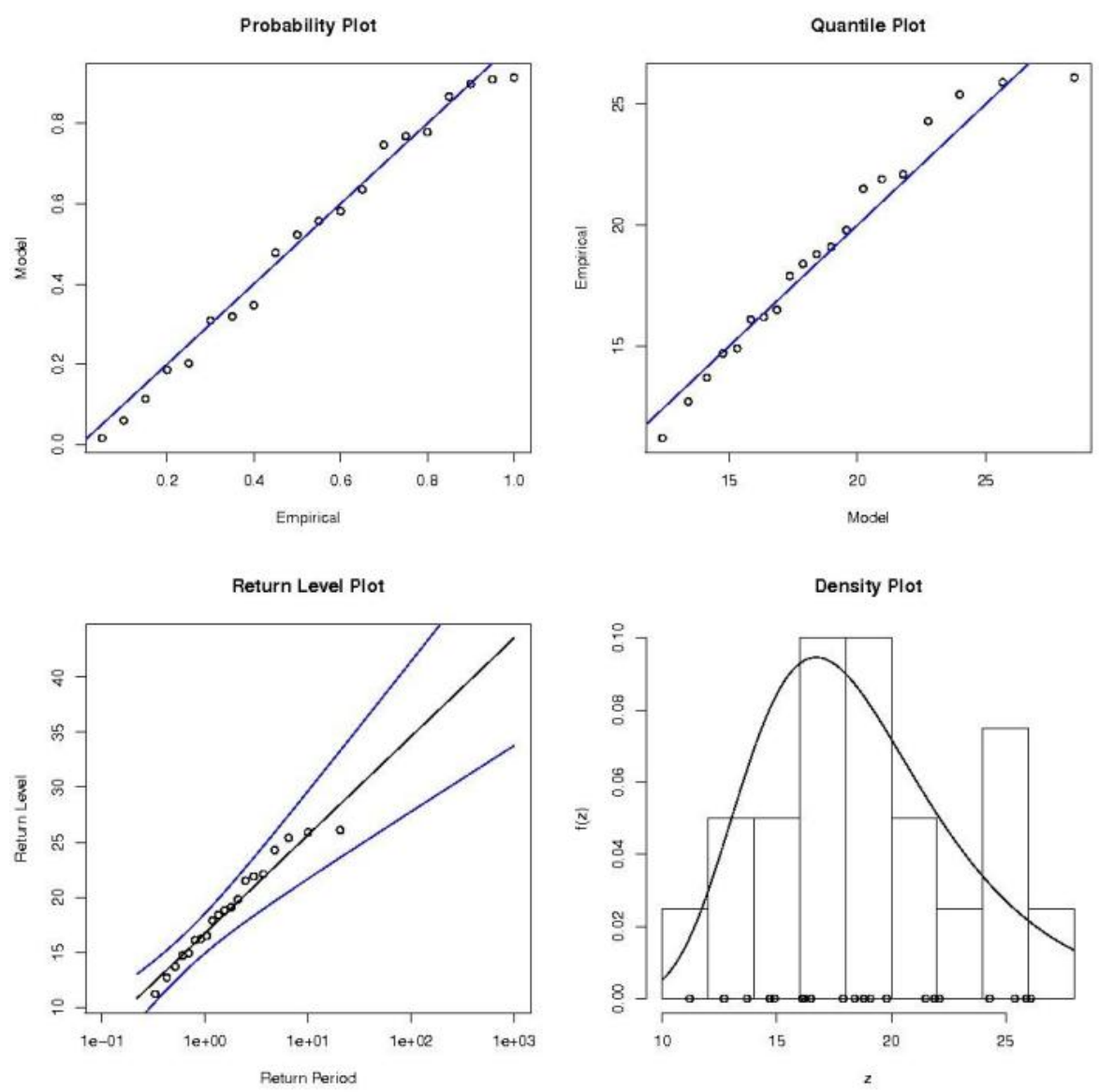

Fig. 2. Diagnostic plots for the Gumbel model fitted to the annual maxima of the 15-min precipitation data at Karama-Plateau (Coles, 2001).

location- and scale-parameter, respectively. To be more precise, the location-parameter $\mu$ specifies the center of the distribution; and the scale-parameter $\sigma$ determines the size of deviations about the location parameter. It was shown that the 2-parameter Gumbel distribution $G$ fitted the limited amount of data for the 3 stations by the model diagnostics plots developed in Coles (2001). As illustration, the diagnostic plots for the Gumbel model fitted to the annual maxima of the 15min precipitation data at Karama-Plateau are shown in Fig. 2 (Coles, 2001; ismev, 2013). The inverse function of the Gumbel distribution $G(x ; \mu, \sigma)$ is given by the following formula:

$a(T)=\mu-\sigma \ln \left[-\ln \left(1-\frac{1}{T}\right)\right]$

Precipitation maxima of specific length with fixed starting points are often derived from digitizing rainfall charts. In this case the specific lengths are determined by the subdivision of the length of the hour on the graph. However, in quantitative hydrology, true maxima, this means maxima in time periods of specific length and with arbitrary starting point are required. In the following, the notation "A-maxima" is used for maxima precipitation amounts with an arbitrary slid- ing starting point where "F-maxima" relate to fixed starting points. Van Montfort $(1990,1997)$ proposed a technique to convert maximum precipitation amounts in specific lengths with fixed starting points into maxima of the same specific length and sliding starting points.

The likelihood function $L$ is defined as:

$L=\prod_{i=1}^{n} g\left(x_{\mathrm{A}, i} ; \mu_{\mathrm{A}}, \sigma_{\mathrm{A}}\right)$

with $x_{i} \leq x_{\mathrm{A}, i} \leq x_{2 i}$, where the indices $\mathrm{A}$ are indicative of Amaxima, $x_{1 i}$ and $x_{2 i}$ are the $i$-th data points with $i=1, \ldots, n$ of the a given length and of its double length, $g$ is the probability density function of the Gumbel distribution $G$ and which is approximated by the expression

$g\left(x_{\mathrm{A}, i} ; \mu_{\mathrm{A}}, \sigma_{\mathrm{A}}\right) \approx \frac{G\left(x_{2 i} ; \mu_{\mathrm{A}}, \sigma_{\mathrm{A}}\right)-G\left(x_{i} ; \mu_{\mathrm{A}}, \sigma_{\mathrm{A}}\right)}{x_{2 i}-x_{i}}$

Practically it is more convenient to work with the $\log$ likelihood function $\ln L$. Optimizing $\ln L$ for $\mu_{\mathrm{A}}$ and $\sigma_{\mathrm{A}}$ is equivalent to optimizing the equation below for $\mu_{\mathrm{A}}$ and $\sigma_{\mathrm{A}}$.

$\ln L=\sum_{i=1}^{n} \ln \left[G\left(x_{2 i} ; \mu_{\mathrm{A}}, \sigma_{\mathrm{A}}\right)-G\left(x_{1 i} ; \mu_{\mathrm{A}}, \sigma_{\mathrm{A}}\right)\right]$ 
Table 2. Optimized values of the parameters of the IDF-curves $i_{T, d}$ for the stations Karama-Plateau, Rubona and Rwerere-Colline in Rwanda.

\begin{tabular}{lcccc}
\hline station & $\mu(\mathrm{mm})$ & $\sigma(\mathrm{mm})$ & $\theta(\mathrm{h})$ & $\eta$ \\
\hline Karama-Plateau & 40.48 & 7.86 & 0.25 & 0.94 \\
Rubona & 44.71 & 11.00 & 0.25 & 0.95 \\
Rwerere-Colline & 40.41 & 5.73 & 0.24 & 0.95 \\
\hline
\end{tabular}

Table 3. Rainfall depths (mm) for return periods $T$ (year), and aggregation times $d(\mathrm{~h})$ based on the adjusted IDF-curves of A-data at the station Rwerere-Colline (Rwanda).

\begin{tabular}{lccccc}
\hline$T$ (year) & 2 & 5 & 10 & 20 & 50 \\
\hline$d=0.25 \mathrm{~h}$ & 20.8 & 24.0 & 26.1 & 28.1 & 30.7 \\
$d=0.5 \mathrm{~h}$ & 28.2 & 32.5 & 35.3 & 38.1 & 41.6 \\
$d=0.75 \mathrm{~h}$ & 32.1 & 37.0 & 40.3 & 43.4 & 47.4 \\
$d=1 \mathrm{~h}$ & 34.6 & 39.9 & 43.4 & 46.8 & 51.1 \\
$d=24 \mathrm{~h}$ & 50.1 & 57.8 & 62.8 & 67.7 & 74.0 \\
\hline
\end{tabular}

Table 4. Rainfall depths ( $\mathrm{mm}$ ) for return periods $T$ (year), and aggregation times $d(\mathrm{~h})$ based on the adjusted IDF-curves of A-data at the station Karama-Plateau (Rwanda).

\begin{tabular}{lccccc}
\hline$T$ (year) & 2 & 5 & 10 & 20 & 50 \\
\hline$d=0.25 \mathrm{~h}$ & 20.9 & 25.2 & 28.1 & 30.8 & 34.3 \\
$d=0.5 \mathrm{~h}$ & 28.5 & 34.4 & 38.3 & 42.0 & 46.8 \\
$d=0.75 \mathrm{~h}$ & 32.6 & 39.3 & 43.8 & 48.0 & 53.6 \\
$d=1 \mathrm{~h}$ & 35.3 & 42.5 & 47.3 & 51.9 & 57.9 \\
$d=24 \mathrm{~h}$ & 52.2 & 63.0 & 70.1 & 76.9 & 85.7 \\
\hline
\end{tabular}

Table 5. Rainfall depths (mm) for return periods $T$ (year), and aggregation times $d(\mathrm{~h})$ based on the adjusted IDF-curves of A-data at the station Rubona (Rwanda).

\begin{tabular}{lccccc}
\hline$T$ (year) & 2 & 5 & 10 & 20 & 50 \\
\hline$d=0.25 \mathrm{~h}$ & 23.5 & 29.6 & 33.5 & 37.4 & 42.3 \\
$d=0.5 \mathrm{~h}$ & 32.1 & 40.3 & 45.7 & 50.9 & 57.6 \\
$d=0.75 \mathrm{~h}$ & 36.6 & 46.0 & 52.2 & 58.1 & 65.8 \\
$d=1 \mathrm{~h}$ & 39.5 & 49.6 & 56.3 & 62.7 & 71.1 \\
$d=24 \mathrm{~h}$ & 57.4 & 72.1 & 81.8 & 91.1 & 103.2 \\
\hline
\end{tabular}

Then the parameters of the Gumbel probability distribution function $G$ for arbitrary starting points are obtained by optimizing the $\log$-likelihood function $\ln L$.

The above-mentioned technique (van Montfort, 1990) is applied to the following couples of lengths (15-30) minutes, (30-60) minutes, (60-120) minutes, and the (1-day, 2days) precipitation data providing estimates of the parameters $\mu_{\mathrm{A}}$ and $\sigma_{\mathrm{A}}$ of the Gumbel probability distributions for Amaxima of 15, 30, $60 \mathrm{~min}$ and 1-day.
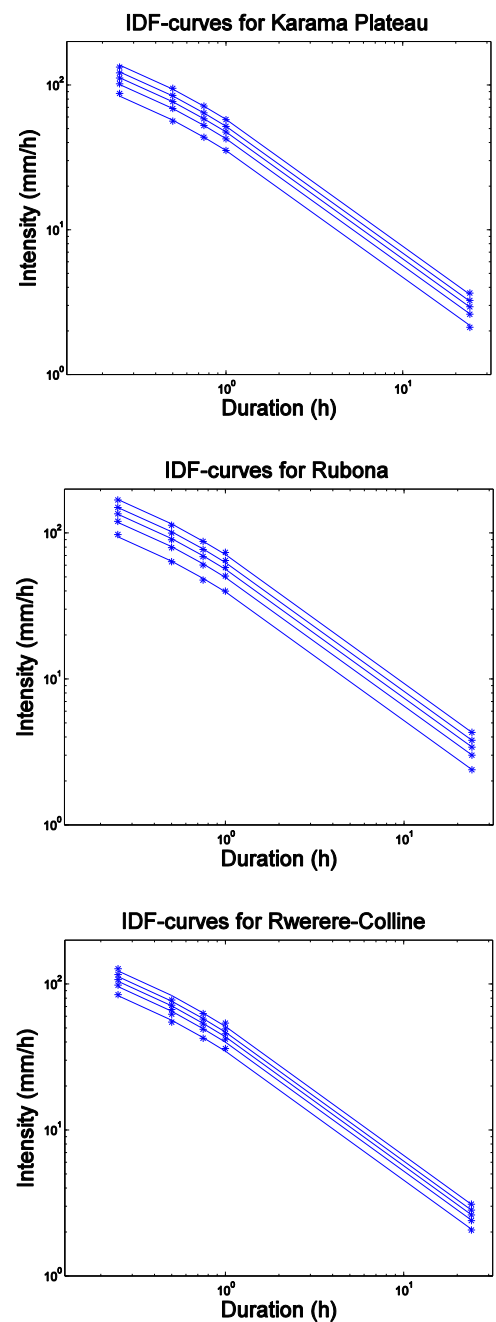

Fig. 3. Intensity-Duration-Frequency (IDF) curves for precipitation at the stations (from top to bottom) Karama-Plateau, Rubona and Rwerere-Colline, Rwanda, using A-type statistical parameters values produced by the van Montfort technique.

Once the parameters of the Gumbel distribution functions are determined the quantiles of the Gumbel distributions are computed corresponding to return periods of 2, 5, 10, 20 and $50 \mathrm{yr}$. The parameters $\mu, \sigma, \theta$ and $\eta$ of the Montana-type formula $i_{T, d}$ are obtained by global optimization techniques (Table 2).

\section{Results}

Figure $3 \mathrm{a}, \mathrm{b}$ and $\mathrm{c}$ show the Intensity-Duration-Frequency (IDF) Montana-type curves for precipitation at the stations Karama-Plateau, Rubona and Rwerere-Colline using the Atype statistical parameters determined by the van Montfort technique (1990). The quantiles for aggregation times $d$ of $15,30,45,60$ and $1440 \mathrm{~min}(0.25,0.5,0.75,1$ and $24 \mathrm{~h})$ and 
for return periods $T$ of $2,5,10,20$ and $50 \mathrm{yr}$ are computed and are given in Tables 3, 4 and 5.

The 3 sets of IDF-curves for precipitation have approximately the same dynamical parameters $\theta$ and $\eta$ but showing differences in the magnitude of intensity; the order of magnitude of the intensity in the stations is (from low to high): Rwerere-Colline (Table 3), Karama-Plateau (Table 4) and Rubona (Table 5).

\section{Discussion}

Intensity-Duration-Frequency (IDF) curves for precipitation were obtained for 3 rainfall stations in different climate regions of Rwanda. Although that information is highly needed as natural hazards such as landslides are frequently observed in the country no such information was available until now for Rwanda. The numerical results obtained for the 3 sites in Rwanda are of similar magnitude to the results for Lubumbashi, Congo (Van de Vyver and Demarée, 2010).

The information is based upon A-maxima of aggregation times with arbitrary starting points. That information was obtained by a van Montfort technique using F-data of aggregation times with fixed starting points. The novelty in the paper is the use of a set of sub-daily precipitation F-data obtained from digitizing precipitation charts in combination with the data set of daily precipitation amounts.

Acknowledgements. The authors sincerely thank the Topical Editor and the Reviewers for their constructive remarks. The authors are grateful to the following libraries having provided the material of the data set: Royal Meteorological Institute of Belgium (RMIB), Université de Liège (ULg), Gembloux Agro-Bio Tech (ULg), Royal Museum for Central Africa, African Library at Brussels, Michigan State University Libraries (Susan Graff), Science \& Engineering Library Boston University (David Fristrom).

Edited by: K. Tokeshi

Reviewed by: two anonymous referees

\section{References}

Bultot, F. and Griffiths, J. F.: Rwanda and Burundi, World Survey of Climatology, Vol. 10, Climates of Africa, edited by: Landsberg, H. E., Elsevier Publishing Company, 349-368, 1971.

Coles, S.: An Introduction to Statistical Modeling of Extreme Values, Springer Series in Statistics, London, 2001.

Crabbé, M.: Recueil d'instructions relatives au réseau d'écoclimatologie (4e édition), République Démocratique du Congo, Institut National pour l'Etude Agronomique du Congo (INEAC), Kinshasa, 1971.

ismev: An Introduction to Statistical Modeling of Extreme Values, CRAN - Package http://cran.r-project.org/web/packages/ismev/ index.html, last access: 23 April 2013.

Koutsoyiannis, D., Kozonis, D., and Manetas, A.: A mathematical framework for studying rainfall intensity-duration-frequency relationships, J. Hydrol., 206, 118-135, 1998.

Stedinger, J. R., Vogel, R. M., and Foufoula-Georgiou, E.: Frequency analysis of extreme events, in: Handbook of Hydrology, 18, edited by: Maidment, D. R., McGraw-Hill, 1993.

Van de Vyver, H. and Demarée, G. R.: Construction of IntensityDuration-Frequency (IDF) curves for precipitation at Lubumbashi, Congo, under the hypothesis of inadequate data, Hydrol. Sci. J., 55(4), 555-564, 2010.

van Montfort, M. A. J.: Sliding maxima, J. Hydrol., 118, 77-85, 1990.

van Montfort, M. A. J.: Concomitants of the Hershfield factor, J. Hydrol., 194, 357-365, 1997. 